\title{
Spectroscopic techniques and the conservation of artists' acrylic emulsion paints
}

\author{
Elizabeth A Willneff ${ }^{*}$, Sven LM Schroeder ${ }^{2}$ and Bronwyn A Ormsby ${ }^{3}$
}

\begin{abstract}
Introduction: Artists' acrylic emulsion paints are used in many contexts such as paintings, murals, sculptures, works on paper and mixed media; and are forming increasing proportions of modern and contemporary art collections. Although acrylic emulsion paints have been the focus of museum-led research over the past decade, the impact of artists' technique and conservation treatment on the upper-most surface of these paints remains essentially unexplored.

Results: This paper summarises previous studies using vibrational (FTIR) spectroscopy and presents initial assessments of paint surfaces using X-ray spectroscopies (XPS and NEXAFS) aimed at characterising artists' acrylic paint film surfaces after natural ageing and wet surface cleaning treatment. Both techniques were found to be well suited for surface-sensitive investigations of the organic materials associated with artists' acrylic paints, including explorations into: (A) cleaning system residues, (B) surfactant extraction from paint surfaces, (C) the identification of migrated surfactant, and (D) monitoring pigment changes at the paint/air interface of paint films.
\end{abstract}

Conclusions: It has been shown is that these $X$-ray spectroscopic techniques can be used for the analysis of almost purely organic materials in a way that complements mass spectroscopic techniques, FTIR and XRF. This investigation forms part of broader, currently ongoing, multi-technique investigation into the properties of artists' acrylic paints and development of conservation treatments for works-of-art made with these materials.

Keywords: Acrylic emulsion; ATR-FTIR; NEXAFS; XPS; Microemulsion; Residues; Pigment; Surfactant; Heritage Science; Conservation

\section{Background}

\section{Modern paints}

The complexities of twentieth century synthetic polymerbased paints such as those based on acrylic emulsion copolymers render them a challenging research topic. Paints created for the industrial, house and artists' paint markets include a wide range of pigments, binders, additives and diluents whose exact composition is proprietary. As a result, understanding the relationships between paint formulation and preservation issues is not particularly straightforward. Not only do formulations vary depending on their intended commercial market or application, but they also change in response to market demands influenced by improvements in technology as well as health and/or environmental legislation. As a consequence, changes are made to formulations on a regular basis.

\footnotetext{
* Correspondence: e.a.willneff@leeds.ac.uk

${ }^{1}$ School of Design, University of Leeds, Leeds LS2 9JT, UK

Full list of author information is available at the end of the article
}

The historical development, properties and conservationrelated concerns about the use of acrylic emulsion paints by artists have been published in detail elsewhere [1-4]. Briefly, the polymeric composition of artists' acrylic emulsion paints has evolved since their introduction to the market. The early formulations were based on a poly ethyl acrylate/methyl methactylate (pEA/MMA) copolymer and some Talens acrylic paints remain based on this [5]. In the 1980s, poly $n$-butyl methacrylate/methyl methacylate ( $n n B A / M M A)$ was widely substituted for $\mathrm{pEA} / \mathrm{MMA}$. In the late 2000s, a further change the base emulsion formulation took place with the incorporation of terpolymers and copolymers of 2-EHA by some artists' paint manufacturers [6].

Surfactants are added to these paints for several purposes. For example, they can act as pigment dispersants, defoamers and emulsion stabilisers [7]. As films mature polyethoxylate type (PEO) non-ionic surfactants (primarily used as emulsion stabilisers) have been shown to segregate 
to the paint film /air interface [7]. The extent of segregation depends on a number of factors including: paint brand (base emulsion type), sample substrate, paint film thickness, pigment type, artists' technique (including dilution and or additions of mediums and other materials), previous conservation treatments, display history (exposure to UV and visible light), environmental history (e.g. exposure to high temperatures), and humidity (particularly high relative humidity) [8,9]. Surfactant levels can also vary due to the pigment types used. It has been noted that cadmium pigmented passages are less likely to have migrated surfactant layers on the paint surface, which may be due to an acceleration of photo-oxidative degradation [10].

Acrylic emulsion paints respond differently to traditional (oil-based) paints with respect to optical properties (such as gloss), physical properties (such as flexibility and softness), ageing, environmental conditions and conservation treatments [2]. Acrylic and other modern and contemporary paintings can also be more vulnerable because they are often large, unframed, unglazed and fewer coatings/ varnishes are used by artists and conservators for the protection of these works. Current conservation practice requires sensitivity to the paint surface and properties, an understanding of the artists' intention, awareness of the fact that these relatively young works of art may not yet have undergone conservation treatment, and that the removal/disturbance of original paint material should be minimised through the use of preventive conservation measures, appropriate conservation materials and minimal intervention where possible.

\section{FTIR spectroscopy}

The popularity of FTIR spectroscopy in conservation science lies in its convenience, relative affordability and long history as an analytical tool [11]. However, although some portable instruments have recently become available, most FTIR equipment requires removing samples from a work of art. Once acquired the samples can be reused, thereby rendering the technique 'semi-destructive'. FTIR is suitable for bulk and surface analysis typically via transmission and ATR configurations, respectively. The surface sensitivity of ATR detection is on the order of micron(s).

FTIR spectroscopy has played a vital role in the routine analysis (identification) and research on modern paints [12]. It has proven useful in understanding the chemistry of artists' acrylic emulsion paints for: identifying base polymer compositions; pigments and filler materials present in paints; evidence for migrated surfactant on various films; the impact of ageing and cleaning treatments on migrated surfactant; the conditions required for surfactant extraction and/or removal and in assessing the efficacy of soiling removal [13]. This has resulted in a significant body of information that has contributed to our understanding of the behaviour and potential vulnerability of acrylic paints. This in turn has led to the development and modification of lower-risk wet-cleaning systems for the removal of accumulated soiling from these paint films $[4,7,11,14,15]$.

Two significant limitations of FTIR spectroscopy include the beam penetration depth and detection limits, which have thus far hindered the exploration the uppermost surfaces of these paint films. Characterising the more subtle changes in the surface of these paint films is essential, as this represents the most vulnerable portion of these paints, i.e., the interaction zone with the surrounding environment as well as being directly affected by conservation treatments.

\section{XPS and NEXAFS}

Both XPS (X-ray photoelectron spectroscopy) and NEXAFS (Near Edge X-Ray Absorption Fine Structure spectroscopy) have had much less application in Heritage Science than X-ray fluorescence (XRF), which is an X-ray spectroscopic tool particularly suitable for inorganic elemental analysis. In the context of modern and contemporary paint research, XPS and NEXAFS offer complementary benefits by broadening the scope of elemental analysis to include organic materials and by providing additional elemental chemical state information covering both the organic and inorganic regions of the periodic table. A summary of the typical sample requirements and analytical capabilities of the techniques is presented here and the reader is referred to excellent textbooks covering the techniques in detail $[16,17]$.

Samples must typically be between $0.5-1 \mathrm{~cm}$ in any direction and compatible with ultra-high vacuum $\left(<10^{-7} \mathrm{mbar}\right)$ although there are microfocusing or imaging systems that can accommodate smaller samples on the order of 100s of microns and instruments that permit higher pressures up to $10^{-4}$ mbar. Apart from the possibility of slight local damage by the X-ray beam, the techniques are nondestructive to the bulk of the sample, enabling samples to be reused for further research.

XPS provides elemental and chemical state (bonding) information by measuring subtle variations in the binding energy of a strongly bound core shell (as opposed to weakly bound valence shell) photoelectron ejected from an atom after absorption of an X-ray photon. The binding energy of the relevant core electrons is element specific, but differences in chemical bonding vary in the binding energy value by $+/-0.1 \mathrm{eV}$ to a few $\mathrm{eV}$. These chemical shifts depend primarily on the charge of the element in question, which is determined by the number and electronegativity of the atoms it is bound to and by its oxidation state. In practice, low resolution spectra of all elements with atomic number $\mathrm{Z}=3-92$ can be rapidly acquired via 
broadband survey spectra that are suitable for quantitative elemental analysis, but do not resolve all features associated with the chemical environment. For more detailed investigations of the chemical state, high resolution spectra are acquired. This makes XPS analysis suitable for a wide range of inorganic and organic materials.

The elements accessible with NEXAFS are restricted by the X-ray photon energies available at monochromated synchrotron radiation source end-stations. The NEXAFS spectra occur in the vicinity of the core electron binding energies probed by XPS. All elements have at least one $\mathrm{K}$ or $\mathrm{L}$ absorption edge suitable for NEXAFS in the photon energy range between $200 \mathrm{eV}$ and 50,000 eV. The photon energy range is conventionally divided into the 'soft' and the 'hard' X-ray range. Soft photon energies, below $2000 \mathrm{eV}$, require the use of vacuum chambers and monochromatization technology based on gratings, while hard X-rays (energies above a few $1000 \mathrm{eV}$ ) penetrate air and are obtained using double crystal monochromators. The transition energy range between $1000 \mathrm{eV}$ and $4000 \mathrm{eV}$ is sometimes referred to as the 'tender' $\mathrm{X}$-ray range.

Acrylic paints contain mostly light elements, including $\mathrm{C}, \mathrm{N}, \mathrm{O}, \mathrm{Ca}$, and $\mathrm{Na}$, which have their NEXAFS spectra in the soft X-ray range. X-ray absorption at higher X-ray energies probes heavier elements in the period table. The acronym XANES (X-ray Absorption Near Edge Structure) is often used instead of NEXAFS to describe the spectra for these elements. Moreover, at higher X-ray energies, the photoelectron interference patterns known as EXAFS (Extended X-ray Absorption fine Structure) can be used to obtain structural information such as bond lengths. XANES and EXAFS are increasingly used in cultural heritage research as well [18].

NEXAFS is particularly sensitive to the bonding environment (coordination and molecular bonds) of organic materials by exploiting significant differences in the spectral fingerprint of their pi vs. sigma orbitals. The benefit of NEXAFS for acrylic paints parallels those observed in other applications of polymer science/coatings, via using the carbon $\mathrm{K}$ edge absorption spectra as a surface sensitive probe for identifying organic materials based on the different bonding environments of their carbon atoms $[17,19,20]$. This is a useful diagnostic tool for distinguishing aliphatic, aromatic and carbonyl carbon species which are commonly found in the context of acrylic paints and also in some of the more advanced cleaning treatments being developed for these materials e.g. microemulsions, gels [4].

It is important to remind the reader that one spectroscopic method in isolation is unlikely to fully reveal the multifaceted properties of paints. As with other spectroscopies, NEXAFS and XPS should ideally be supported by a suite of analytical tools including mass spectrometry
(ESI-MS, DESI-MS), microscopy (optical, SEM, AFM), and thermal analysis techniques (DSC, TGA, DMA).

The results presented below are a subset of a broader ongoing investigation into the response of artists' acrylic paint films to wet-surface cleaning treatments used for the removal of accumulated soiling. To explore this, selected representative wet-cleaning systems, some established and some novel, were applied to prepared acrylic paint films from paints made by Golden Artist Colors and Talens (detailed elsewhere [13]). In some cases a commonly executed clearance step (using deionised water or a low aromatic content hydrocarbon solvent) was applied with the aim of removing system residues. In other cases the clearance step was omitted to explore instrumental detection limits. Several established and novel wet cleaning systems are under investigation. Here we discuss those based on: deionised water, a low aromatic content petroleum spirit (Shellsol D40), and a mineral spirits continuous phase water-in-oil microemulsion system containing a sodium $(\mathrm{Na})$ sulfonate (LAS) anionic surfactant, which has been described in detail elsewhere [4].

\section{Results and discussion}

As the bulk of the FTIR spectroscopy-based research exploring acrylic emulsion paint behaviour has been published $[7,10,11]$, the next section focuses on information gained through the use of XPS and NEXAFS spectroscopies. Several aspects of ongoing research are highlighted including (a) residues from applied cleaning treatments, (b) surfactant extraction from the paint surface, (c) surfactant migration following natural ageing and, (d) response of pigment to cleaning treatments.

\section{A. Exploring wet-cleaning system residues}

Ideally, wet cleaning treatments used to remove accumulated grime and soiling will leave minimal residues on the cleaned surfaces of works of art. However, with some of the newer cleaning treatments developed recently, the extent to which residues remain on unvarnished paint surfaces is unknown. MS, FTIR, and fluorescence detection of labelled materials have been used to investigate residues from applied cleaning systems, particularly surfactant residues [21].

To explore the complementary benefits of XPS and NEXAFS at identifying surface residues, acrylic paint films were swabbed with different cleaning systems. XP survey spectra identified increased amounts of $\mathrm{Na}$ and sulfur (S) after swabbing with a microemulsion on an unsoiled paint film (without a subsequent clearance step). This was attributed to residues of LAS anionic surfactant in the microemulsion [13]. Additional evidence for residues was provided by the high resolution $\mathrm{C}$ (carbon) 1s XP spectra (Figure 1A). In contrast to the survey spectra which 

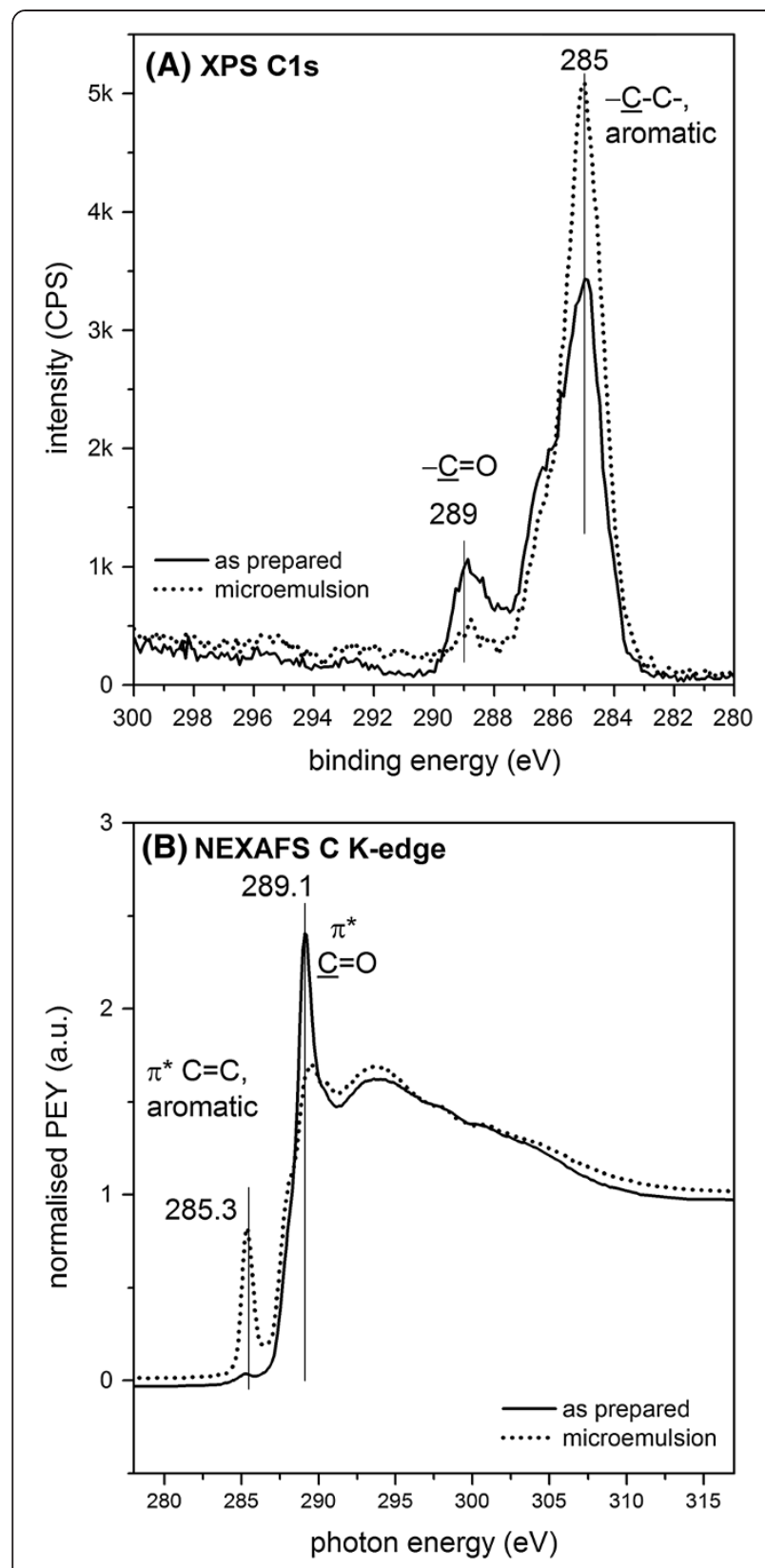

Figure 1 XPS and NEXAFS of Carbon Species in Cleaning System Residues. C1s XP spectra (A) and C K-edge NEXAFS spectra (B) of Talens PY3 yellow paint film before ('as prepared') and after ('microemulsion') swabbing with a microemulsion containing LAS surfactant (no clearance step).

identified elemental differences in the paint films before and after these uncleared wet cleaning treatments, the $\mathrm{C} 1 \mathrm{~s}$ spectra identified differences in the chemical state of carbon which were representative of changes in the composition of organic material at the surface of the paint film (e.g. binder vs. surfactant). The peak at approx. $289 \mathrm{eV}$ associated with the $\mathrm{C}=\mathrm{O}$ (carbonyl) groups of the acrylic resin almost disappeared after microemulsion swabbing, indicating that quantities of the LAS surfactant (which does not contain carbonyl groups) remained on the paint surface.

The potential benefits of NEXAFS over XPS for identifying these residues were also explored. The $\mathrm{C}$ K-edge NEXAFS spectrum after swabbing with a microemulsion (uncleared) was easily distinguished from the untreated paint film (Figure 1B). This was possible because of the significantly different absorption energies for aromatic $(\sim 285 \mathrm{eV})$ and carbonyl carbons $(\sim 289 \mathrm{eV})$ associated with the LAS surfactant in the microemulsion, and the acrylic binder respectively. Likewise, the $\mathrm{O}$ (oxygen) K-edge NEXAFS spectra (Figure 2B) were also diagnostic for the presence of these residues via the carbonyl oxygen $(\sim 532 \mathrm{eV})$ and singly bound oxygen $(\sim 540 \mathrm{eV})$ of the acrylic binder and the sulfonate anionic headgroup of the surfactant. The corresponding differences in the O1s XP spectra before and after swabbing with the microemulsion were less distinct (Figure 2A). This relatively unspecific nature of O1s spectra is well known in the surface analysis community and stems from the fact that there are various reactive and/or strongly adsorbing oxygen-containing contaminants in the ambient environment, including $\mathrm{O}_{2}, \mathrm{H}_{2} \mathrm{O}, \mathrm{CO}_{2}$ (forming surface carbonates) as well as many biological molecules (e.g. fatty acids, polysaccharides). All of these can be superimposed on the O1s spectra of a sample.

In general, because of less surface sensitivity (and hence less influence of oxygen-containing contaminants) oxygen NEXAFS spectra offered a clearer distinction between the surfactant and binder than the O1s XPS, which highlights a possible benefit of the technique. However, this needs to be balanced against the ease of accessing a lab based (XPS) vs. an exclusively synchrotron based (NEXAFS) technique.

\section{B. Surfactant extraction (from the paint film surface)}

In addition to residues, the impact of wet cleaning treatments on additives in the bulk paint film has also been investigated. As an example, after aqueous (deionised water) swabbing for 20 swab rolls (one roll there/back) on an unsoiled Talens yellow (PY3) paint film, evidence for the earliest stages of surfactant extraction from the paint film surface (rather than removal of previously migrated surfactant from the paint surface) was visible in $\mathrm{C} 1 \mathrm{~s} \mathrm{XP}$ spectra by an increase in the $\mathrm{C}-\mathrm{O}$ ether contribution at approx. $286.5 \mathrm{eV}$ ([13]). This subtle change was mirrored in the NEXAFS spectra of carbon (Figure 3A) and oxygen (Figure 3B). The changes in both spectra are slight. However the spectra after water swabbing became more similar to the spectrum of pure surfactant. (Notably, these changes were not readily evident in corresponding ATR-FTIR spectra.) Significantly, both the carbon and oxygen NEXAFS spectra of Golden yellow, which is surfactant 'lean' relative to the Talens paint film, were 

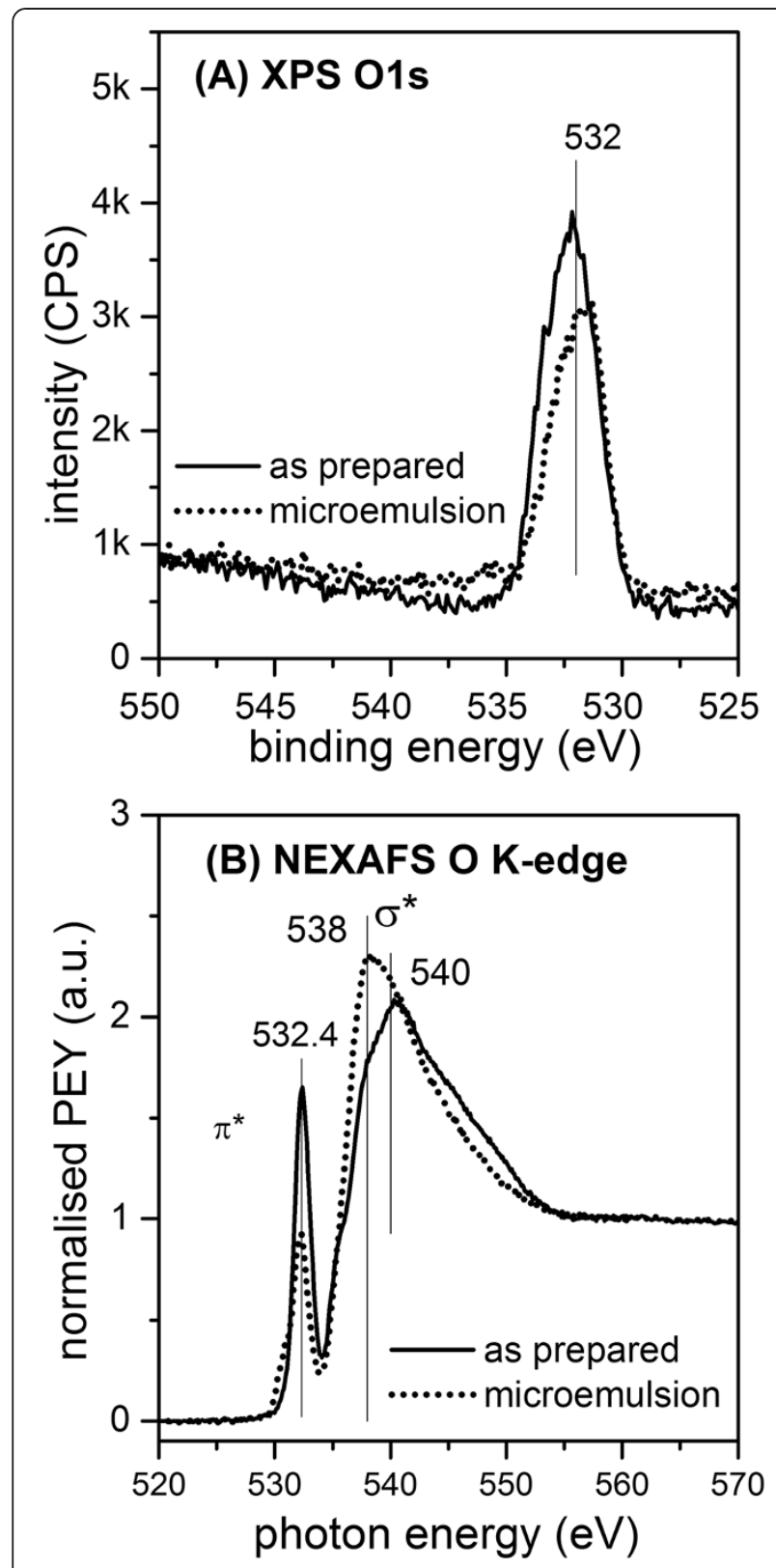

Figure 2 XPS and NEXAFS of Oxygen Species in Cleaning System Residues. O1s XP spectra (A) and O K-edge NEXAFS spectra (B) of Talens PY3 yellow paint film before and after swabbing with a microemulsion containing LAS surfactant (no clearance step).

unchanged after water swabbing. Exposure of these paint films to neutral to basic solutions of low conductivity such as the DI water used here is known to promote swelling and hence the mobility of additives, such as surfactants [22]. This is an interesting finding as surfactant extraction from the upper surface of acrylic paint films has not yet been identified as occurring from swabbing action alone; thus far publications have focussed on identifying migrated surfactant on paint surfaces and/or extraction of bulk film surfactant through immersion in water and other solvents
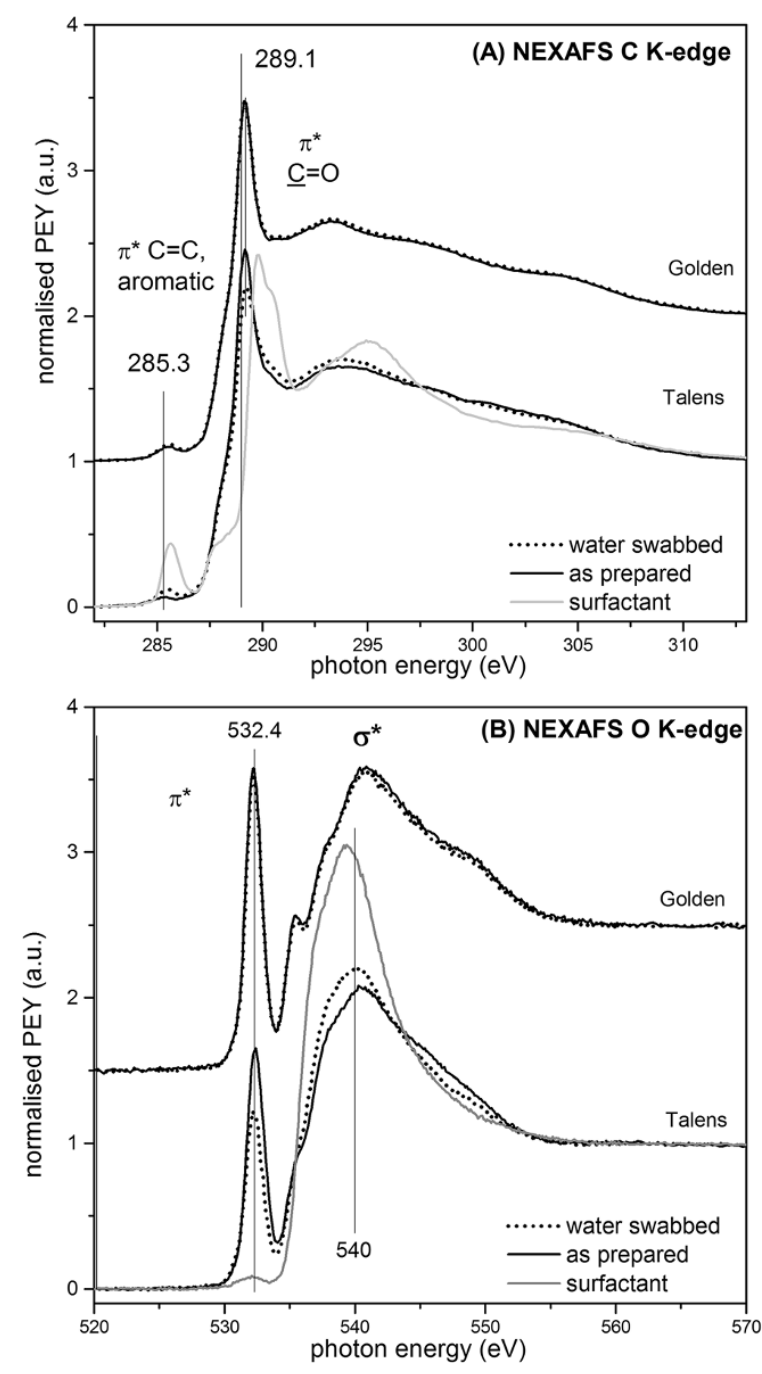

Figure 3 NEXAFS and Surfactant Extraction. Carbon (A) and oxygen (B) NEXAFS spectra of a Talens PY3 yellow paint film after swabbing with water showed features similar to a reference spectrum of Triton ${ }^{\mathrm{TM}} \mathrm{X}-405$ providing evidence for early stages of aqueous surfactant extraction from the bulk of the paint film. No change was visible on a Golden paint film.

$[7,23]$. It is highly unlikely that the aqueous extraction of very minor amounts of surfactant from paint film surfaces would result in significant changes in paint properties [7], particularly for aged paints. However this confirms that surfactants within acrylic paint films may be vulnerable to aqueous swabbing action. This provides further evidence that minimising the swelling potential of wet-cleaning systems is advisable where possible (through keeping liquids to a minimum and using cleaning systems tailored towards the low-swelling conditions described above).

\section{Surfactant migration}

As mentioned in the introduction, PEO type surfactants (e.g. Triton $\left.{ }^{\mathrm{Tm}} \mathrm{X}-405\right)$ are known to migrate to the paint 
film surface. Although migrated surfactant can be detected visually when present in significant quantities and chemically by FTIR and MS techniques, the impact on XPS and NEXAFS spectra is unknown. Where detailed surface chemical analysis of paint films is necessary, understanding the impact of migrated surfactant on these spectra is essential. With this in mind, XPS and NEXAFS analyses of a Talens PY3 yellow paint film after 2 years of natural ageing, which was determined with ATR-FTIR spectroscopy to have significant quantities of migrated surfactant, were compared to those of recently prepared paint films without migrated surfactant. Differences between the two films were apparent in both the $\mathrm{C} 1 \mathrm{~s}$ (Figure 4A) and the O1s (Figure 4B) XP spectra. In the $\mathrm{C} 1 \mathrm{~s}$ XP spectrum, evidence for decreased acrylic binder content (conversely more migrated surfactant after ageing) was provided by the less intense $\mathrm{C}=\mathrm{O}$ carbonyl peak at $289 \mathrm{eV}$ in the $\mathrm{C} 1 \mathrm{~s} \mathrm{XP}$ spectrum, associated with the acrylic binder. Furthermore a -C-O- ether peak at approx. $286.5 \mathrm{eV}$ was greatly enhanced after ageing. Since ether groups are primary functional groups of the migrated PEO type surfactant, both of these features afforded a spectrum for the aged paint film which was similar to that of a PEO surfactant such as Triton ${ }^{\text {Tx }} \mathrm{X}$ 405. However the O1s spectrum of the aged sample was

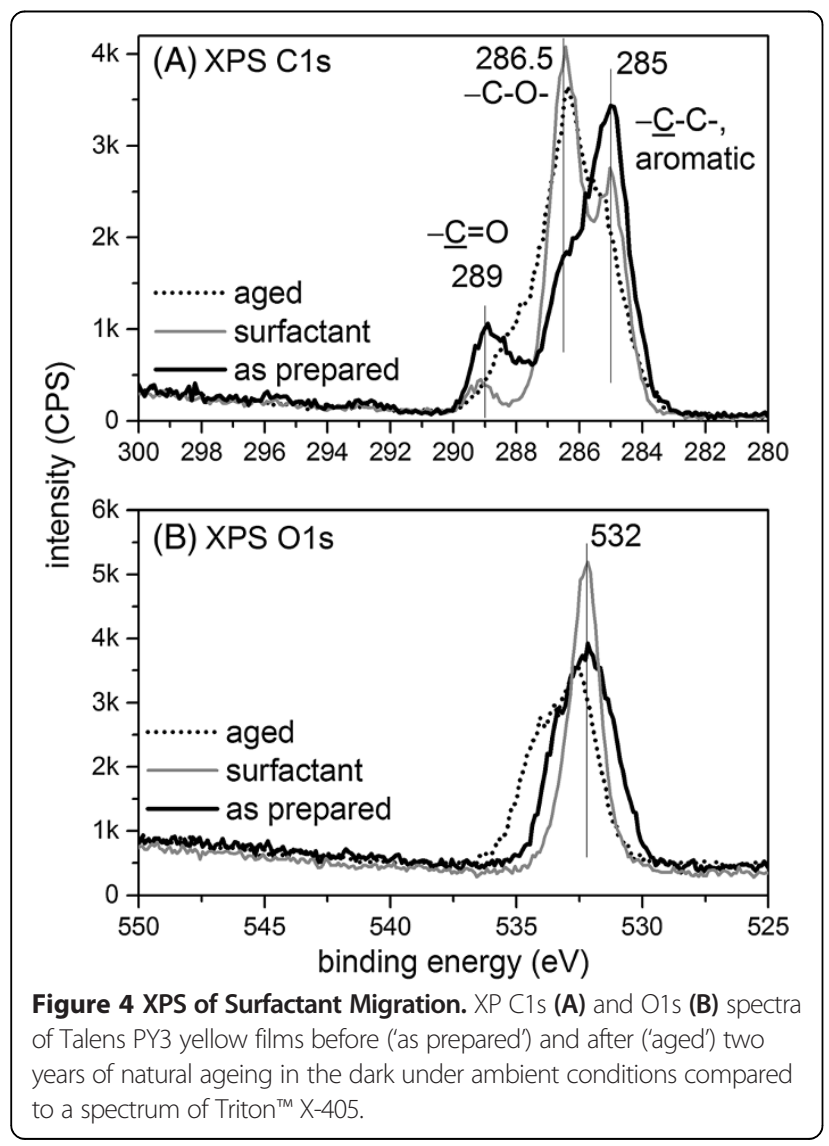

not as similar to that of the pure surfactant. Generally, in addition to the contamination issues mentioned above, O1s XP spectra respond less specifically to changes in chemical environment than the corresponding carbon XP spectra of polymeric systems and therefore oxygen spectra are used less often as diagnostic tools for assigning chemical species. This contrasts with the O K-edge NEXAFS spectra (discussed below) which were, because of less surface sensitivity (see above), more readily diagnostic for the presence of migrated surfactant.

Migrated surfactant also affected the NEXAFS spectra (Figure 5). Qualitatively the carbon NEXAFS spectra (Figure 5A) of the naturally aged paint film had more complex features, similar to the spectrum of $\operatorname{Triton}^{\text {Tn }} \mathrm{X}$ 405 surfactant, than the younger paint film. The intensity of the $\pi^{*}$ transition associated with $-\mathrm{C}=\mathrm{C}$ - or aromatic $\mathrm{C}-\mathrm{C}$ bonds as well as of $\sigma^{*}$ transitions increased while the $\pi^{*}-\mathrm{C}=\mathrm{O}$ transition shifted to higher photon energies. The corresponding oxygen NEXAFS spectra were less complex and made up of two primary contributions from single bound $\left(\sigma^{*}\right)$ and double bound $\left(\pi^{*}\right)$ oxygen species at approx. 540 and $532 \mathrm{eV}$ respectively (Figure 5B). The spectrum of the naturally aged paint film was clearly more like that of a film of pure surfactant. A detailed

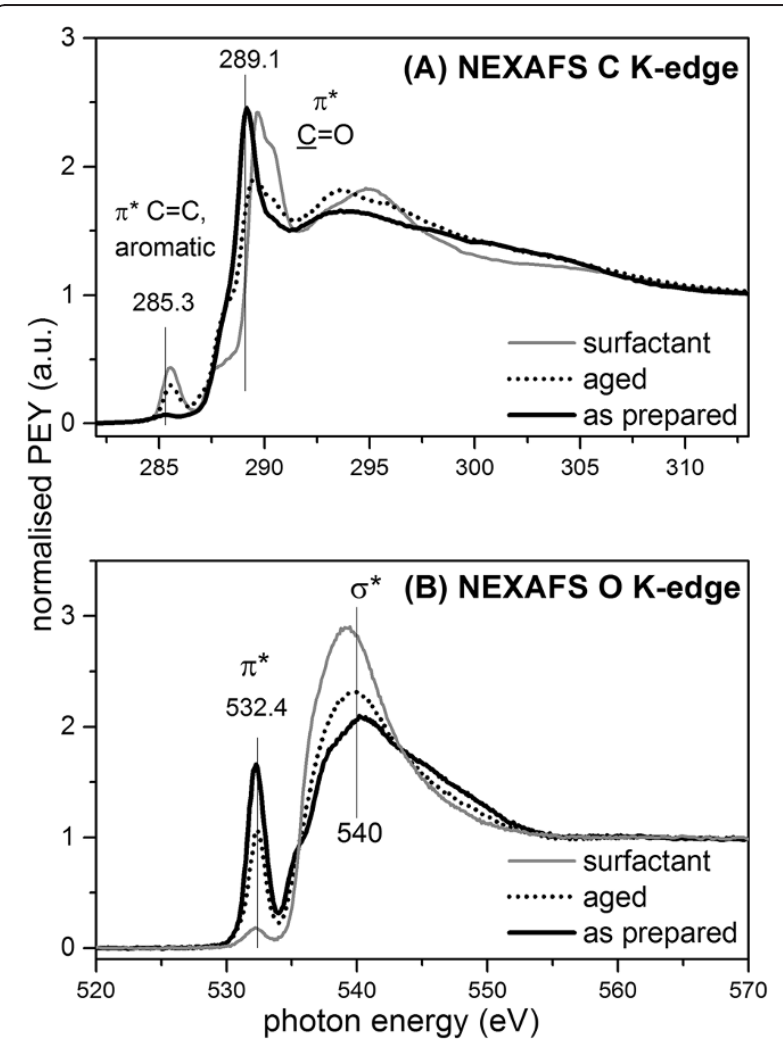

Figure 5 NEXAFS of Migrated Surfactant. NEXAFS C (A) and O (B) K-edge spectra of Talens PY3 yellow films before ('as prepared') and after ('aged') two years of natural ageing in the dark under ambient conditions compared to a spectrum of Triton ${ }^{T M} X-405$. 
analysis of these spectra is underway to understand the origins of these features. The qualitative interpretation of the spectra indicates for now that both of these techniques can be used to detect migrated surfactant and subsequent removal through treatment and/or environmental degradation. Work is underway to determine if it might be possible to identify migrated surfactant with XPS and/or NEXAFS before it can be readily identified with ATRFTIR as appears to have been the case with the extracted surfactant following water swabbing (Figure 2 and [13]).

\section{Pigment behaviour in response to cleaning treatment}

One further aspect of paint film chemistry being investigated includes changes in pigment behaviour in response to wet cleaning treatments. Pigment loss (transfer of pigment to swabs/cleaning materials and/or solubility of pigments) during cleaning treatments is undesirable and cleaning treatments are designed to minimise this.

Pigment loss has been observed as more likely with some pigments, and for some paint brands more than others for a given pigment. As part of this preliminary work, the utility of XPS and NEXAFS for identifying changes in surface (exposed) pigment levels was also explored. XP spectra of chlorine were used to monitor changes in PY3 surface pigment concentration after swabbing artificially soiled and unsoiled paint films with deionised water and petroleum spirits using 20 swab rolls (Figure 6). The $\mathrm{Cl}$ signals were virtually indistinguishable in all cases from the baseline except after swabbing an unsoiled Talens PY3 yellow paint film with petroleum spirits. In this case, the $\mathrm{Cl}$ signal increased significantly above the baseline indicating an increased pigment concentration (detection) at the surface of the paint

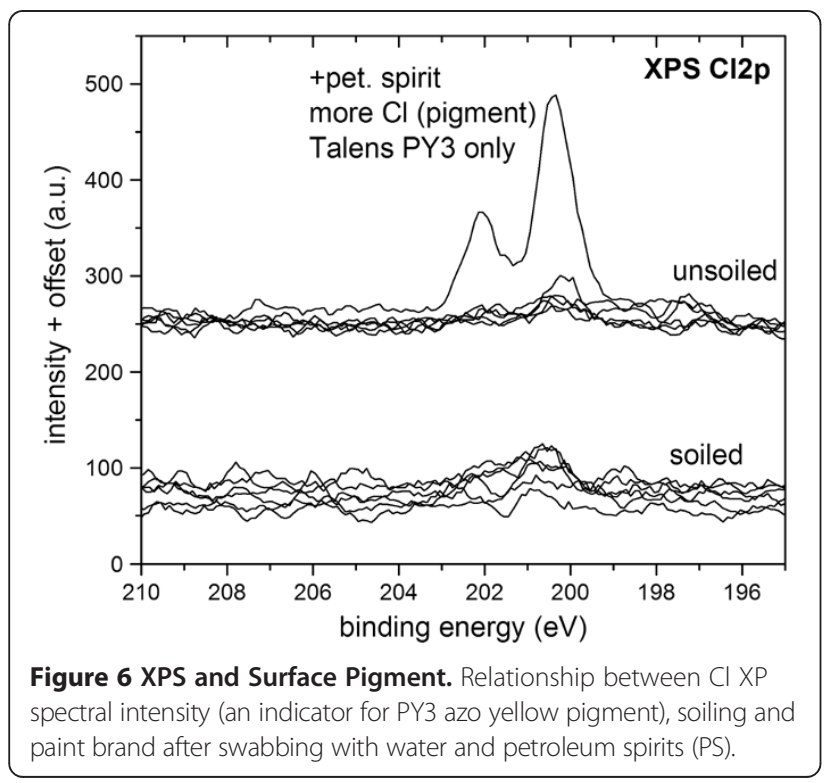

film. This concurs with reports of increased pigment transfer on some paints during the use of cleaning treatments based on petroleum spirits [13,15]. Notably, however, the $\mathrm{Cl}$ signal after PS swabbing on the soiled Talens film did not increase. Here the soiling layer may have slowed down the transport of the solvent to the underlying paint film, presumably only until the greasy soil has been dissolved/penetrated.

The NEXAFS N (nitrogen) K-edge spectra offer additional insight into the behaviour of the PY3 pigment (Figure 7). The spectrum of an unsoiled sample swabbed with petroleum spirits appears to be very similar to that of pure PY3 pigment. The control and water swabbed samples, on the other hand, were unlike the pigment but similar to each other. Interestingly, these differences were only observed at the most surface sensitive detector settings ( $-200 \mathrm{~V}$ electron grid bias (EGB)); when acquiring spectra over a slightly greater depth from the surface (-50 V EGB), all spectra (regardless of wet cleaning treatment type) were very similar and unlike pure pigment. This suggests that there may be a layer of unbound (or poorly bound) pigment localised to the very uppermost portion of the paint film after cleaning with the hydrocarbon solvent.

The increased PY3 pigment mobility could have several origins. The solubility of pure PY3 pigment in petroleum spirits is not high and is therefore unlikely to be a major contributing factor. Although swelling data shows that these types of paints do not swell extensively in non-polar solvents [14], the response of the uppermost paint surface to solvent exposure and mechanical action may result in

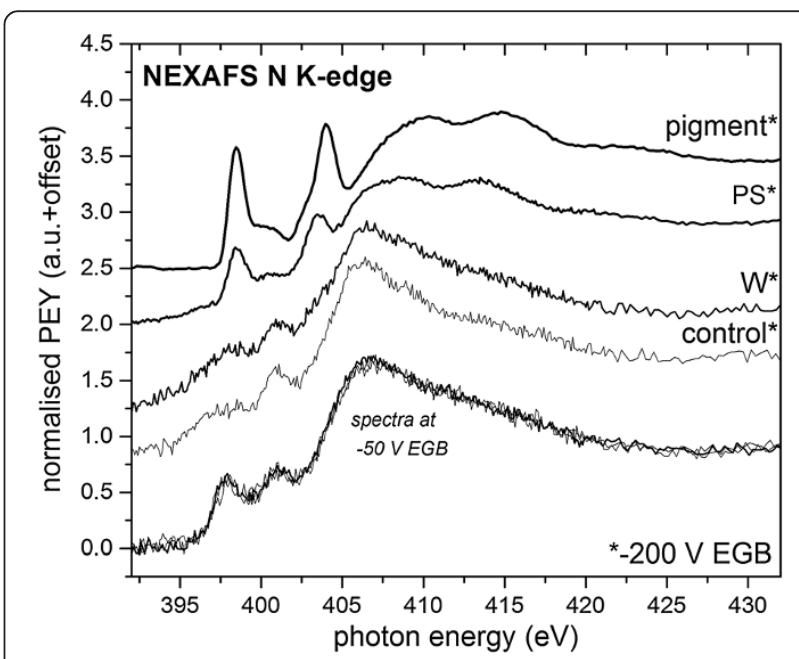

Figure 7 NEXAFS and Surface Pigment. NEXAFS N K-edge spectra of Talens PY3 yellow paint film after wet swabbing with water (W) and petroleum spirit (PS) collected at very high (-200 V EGB) and high ( -50 V EGB) surface sensitivities in comparison to PY3 azo yellow pigment. 
pigment separation from the binder, which requires further exploration.

\section{Conclusions}

We have presented initial investigations of acrylic paint surfaces using two X-ray spectroscopic techniques that are hitherto not commonly used for examining organic materials in the context of heritage science. If samples are compatible with the measurement requirements (most notably ultra-high vacuum), XPS provides chemical state information for elements across the entire periodic table, while NEXAFS provides chemical and molecular bonding information for elements with absorption $\mathrm{K}$ or $\mathrm{L}$ edges between $200-1200 \mathrm{eV}$ i.e. in the soft X-ray range. Both techniques were found to be well suited for surface-sensitive investigations of the organic materials associated with artists' acrylic paints, including explorations into: (A) cleaning system residues, (B) surfactant extraction from paint surfaces, $(C)$ the identification of migrated surfactant, and (D) monitoring pigment changes at the paint/air interface of paint films. At this early stage it is not possible to identify direct implications for applied conservation practice other than reiterating the need to keep solvent exposure to a minimum during surface cleaning treatment. It has been shown that these soft X-ray spectroscopic techniques can be used for the analysis of almost purely organic materials, paints in this case but also plastics and related materials, being investigated in the context of cultural heritage in a way that complements mass spectroscopic techniques, FTIR and XRF. This investigation forms part of broader, currently ongoing, multi-technique investigation into the properties of artists' acrylic paints and development of conservation treatments for works-of-art made with these materials.

\section{Experimental}

The method of paint film preparation, application of artificial soiling, and wet cleaning treatments used to prepare the samples as well as details of the experimental techniques have previously been published [13] and are summarised here.

\section{Paint film preparation}

Artists paints, Golden Heavy Body Acrylics Hansa Yellow Light and Talens Rembrandt Azo Yellow Lemon, both containing PY3 azo yellow organic synthetic pigment, were applied to a triple primed canvas with a draw-down technique on a Sheen Instruments film caster, to a wet thickness of approximately $800 \mu \mathrm{m}$ and dry thickness of $200-250 \mu \mathrm{m}$, as measured with a digital caliper. The resin for the Golden paint was a $n$ (BA/MMA copolymer while the resin for the Talens paint was a $\mathrm{p}(\mathrm{EA} / \mathrm{MMA}$ copolymer with detectable amounts of a chalk $\left(\mathrm{CaCO}_{3}\right)$ extender.
Samples discussed here underwent simulated cleaning treatments with the following wet cleaning agents. The water (W) was deionized (DI) (Purite, D700 deionizer). A 100\% aliphatic petroleum spirit (PS) (VWR International) with a boiling point of $120-160^{\circ} \mathrm{C}$ was used as received. The novel Dow microemulsion (ME) was a water-in-oil microemulsion comprised of proportions of lauryl ammonium sulphate (LAS), low molecular weight alcohol-based cosolvents, a Shellsol D38 mineral spirits solvent continuous phase and deionized water [4] To assess cleaning efficacy, an artificial soiling mixture [15] approximating typical indoor particulate soiling which might accumulate passively over many years was brushed onto some samples (referred to as 'soiled') and allowed to dry before cleaning treatments.

Each cleaning agent was applied to an approximately $1 \mathrm{~cm}^{2}$ square area of the paint film by dipping a prerolled cotton swab into the solution once, and then rolling the swab back and forth (1 roll) across the paint film 20 times without application of a subsequent clearance step (which would be standard conservation practice) and dried in ambient conditions. Samples for spectroscopic analysis were prepared using a single hole punch, resulting in circular disks with a diameter of $6 \mathrm{~mm}$.

To obtain reference spectra (labelled 'surfactant') of the type of PEO surfactant often found in these types of paints [7], films of dried surfactant on paint films were prepared for the NEXAFS and XPS measurements by brushing aqueous solutions $(50 \% \mathrm{v} / \mathrm{v})$ of Triton $^{\mathrm{m} \mathrm{M}} \mathrm{X}-405$ (70 wt\% in water, Aldrich) onto an unsoiled Talens PY3 yellow paint film and the triple primed canvas respectively. The films were allowed to dry under ambient conditions.

\section{X-ray Photoelectron Spectroscopy (XPS)}

$\mathrm{XP}$ spectra were collected from samples mounted on double sided adhesive tape with a Kratos Axis Ultra spectrometer operating with a monochromatic Al $\mathrm{K} \alpha$ $\mathrm{X}$-ray anode $(1486.69 \mathrm{eV})$ at 180 watts $(15 \mathrm{kV}, 12 \mathrm{~mA})$, a hemispherical analyser in electrostatic mode ( $\mathrm{p}<10^{-7}$ mbar) and charge neutralisation. Survey XP spectra were acquired in a single sweep with a pass energy of $80 \mathrm{eV}$, in steps of $0.35 \mathrm{eV}$ and dwell time of $150 \mathrm{~ms}$, giving collection times of approx. 9 min per spectrum. High resolution $\mathrm{XP}$ spectra were acquired in a single sweep with a pass energy of $20 \mathrm{eV}$, in steps of $0.1 \mathrm{eV}$ with a dwell time of $200 \mathrm{~ms}$, giving a collection time of 1 min per spectrum. Data analysis was carried out with CasaXPS. Binding energies were referenced to a primary hydrocarbon peak set to $285.0 \mathrm{eV}$, which required a correction of approximately $+3-3.5 \mathrm{eV}$ to the experimental data. XP spectra acquired of chlorine present at low concentration were noisy and smoothed for better clarity. 


\section{Near-edge X-ray Absorption Fine Structure (NEXAFS)} NEXAFS measurements were performed at the U7a beamline of the National Synchrotron Light Source (NSLS) at Brookhaven National Laboratory, NY [24]. Spectra were collected in partial electron yield (PEY) mode via a channeltron electron multiplier. The entrance grid bias (EGB), which permits tuning of the surface selectivity of the spectra, was $-50 \mathrm{~V}$ for all spectra except for several spectra in Figure 7 acquired at $-200 \mathrm{~V}$ (more surface selective). The monochromator grating had $600 \mathrm{l} / \mathrm{mm}$ at the $\mathrm{C}$ and $1200 \mathrm{l} / \mathrm{mm}$ at the $\mathrm{O}$ K-edges respectively. The energy scale was calibrated at the $\mathrm{C}$ K-edge by setting the first maximum in the spectrum of the amorphous carbon grid to $285.1 \mathrm{eV}$. At the $\mathrm{N}$ K-edge the first maximum of the TiN reference spectrum was set to $400.6 \mathrm{eV}$ while at the $\mathrm{O}$ edge the $\mathrm{I}_{0}$ first minimum was aligned to $531.2 \mathrm{eV}$. Spectra were normalised in intensity via the Autobk subroutine in Athena [25].

\section{Abbreviations}

ATR-FTIR: Attenuated Total Reflection-Fourier Transform Infrared (spectroscopy); AFM: Atomic Force Microscopy; EGB: Entrance grid bias; LAS: Linear alkyl sulfonate; ME: Microemulsion; NEXAFS: Near-Edge X-ray Absorption Fine Structure; PEO: Polyethoxylate; PEY: Partial electron yield; PS: Petroleum spirit; UHV: Ultra-high vacuum; XPS: X-ray Photoelectron Spectroscopy.

\section{Competing interests}

The authors declare that they have no competing interests.

\section{Authors' contributions}

BAO developed the intellectual background to the work which is summarized in the introduction and presented in previous publications and also presented the conference paper on which this article is based. EAW and SLMS carried out XPS measurements. SLMS carried out NEXAFS measurements. EAW performed the analyses with advice on interpretation provided by SLMS and BAO. All authors conceived of this study applying X-ray spectroscopies, participated in its design and coordination, and drafted the manuscript.

\section{Acknowledgements \\ EAW thanks the AHRC/EPSRC Science and Heritage Programme for funding her Postdoctoral Research Fellowship. We are grateful for support in NEXAFS measurements by Dr Cherno Jaye and Dr Daniel Fischer (NSLS), as well as Dr Joanna Stevens and Mr Adrian Gainar (University of Manchester). Use of the National Synchrotron Light Source, Brookhaven National Laboratory, was supported by the U.S. Department of Energy, Office of Science, Office of Basic Energy Sciences, under Contract No. DE-AC02-98CH10886. \\ Author details \\ ${ }^{1}$ School of Design, University of Leeds, Leeds LS2 9JT, UK. ${ }^{2}$ School of Chemical and Process Engineering, University of Leeds, Leeds LS2 9JT, UK. \\ ${ }^{3}$ Tate, Millbank, London SW1P 4RG, UK.}

Received: 3 June 2014 Accepted: 17 October 2014

Published online: 12 November 2014

\section{References}

1. Crook J, Learner T (Eds): The Impact of Modern Paints. London: Tate Gallery; 2000

2. Jablonski E, Learner T, Hayes J, Golden M: Conservation concerns for acrylic emulsion paints: a literature review. Rev Conserv 2003, 4:1-13.
3. Learner TJS, Smithen P, Krueger JW, Schilling MR (Eds): Modern Paints Uncovered: Proc. from Modern Paints Uncovered Symposium. Los Angeles: Getty Conservation Institute; 2007

4. Keefe BM, Ormsby B, Soldano A, Phenix A, Learner T, Tucker C, Behr A, Meyers G, Rheinhardt C, Boomgaard T, Peitsch C: Art and industry: novel approaches to the evaluation and development of cleaning systems for artists' acrylic latex paints. CoatingsTech 2011, 8(9):30-43.

5. Ormsby BA, Learner TJS, Foster GM, Druzik JR, Schilling MR: Wet cleaning acrylic emulsion paint films: an evaluation of physical, chemical, and optical changes. In Modern Paints Uncovered: Proceedings from Modern Paints Uncovered Symposium. Edited by Learner TJS, Smithen P, Krueger JW, Schilling MR. Los Angeles: Getty Conservation Institute; 2007:187-198.

6. Ormsby B, Hodgkins R, von Aderkas N: Preliminary investigations into two new acrylic emulsion paint formulations: W\&N artists' acrylic colours and golden open acrylics. e-Preservation Sci 2012, 9:9-16.

7. Ormsby $B$, Learner $T$ : The effects of wet surface cleaning treatments on acrylic emulsion artists' paints - a review of recent scientific research. Rev Conserv 2009, 10:29-41.

8. Ormsby B, Kampasakali E, Learner T: Surfactants and acrylic dispersion paints: evaluating changes induced by wet surface cleaning treatments. In New insights into the Cleaning of Paintings: Proc from Cleaning 2010 Int Conf Univ Politécnica Valencia and Museum Conserv Institute. Edited by Mecklenburg MF, Charola AE, Koestler RJ. Washington, DC: Smithsonian Institution Scholarly Press; 2013:159-164.

9. Ormsby B, Learner T, Schilling M, Druzik J, Khanjian H, Carson D, Foster G, Sloan M: The effects of surface cleaning on acrylic emulsion paintings-a preliminary investigation. Oberflachenreinigung 2006, 2:7-2

10. Ormsby B, Smithen P, Hoogland F, Miliani C, Learner T: A scientific evaluation of surface cleaning acrylic emulsion paintings. In Preprints ICOM-CC 15th Trienn Conf New Delhi; 2008:865-873.

11. Ormsby BA, Kampasakali E, Miliani C, Learner T: An FTIR-based exploration of the effects of wet cleaning treatments on artists' acrylic emulsion paint films. e-Preservation Sci 2009, 6:186-195.

12. Learner TJS: Analysis of Modern Paints. Los Angeles: Getty Conservation Institute; 2005.

13. Willneff EA, Ormsby BA, Stevens JS, Jaye C, Fischer DA, Schroeder SLM: Conservation of artists' acrylic emulsion paints: XPS, NEXAFS and ATR-FTIR studies of wet cleaning methods. Surf Interface Anal 2014, doi:10.1002/sia.5376.

14. Kampasakali E, Ormsby B, Phenix A, Schilling M, Learner T: A preliminary study into the swelling behavior of artists' acrylic emulsion paint films. In Preprints ICOM-CC 16th Trienn Conf Lisbon. ; 2011:1-8.

15. Ormsby BA, Soldano A, Keefe MH, Phenix A, Learner T: An empirical evaluation of a range of cleaning agents for removing dirt from artists' acrylic emulsion paints. AIC Paint Spec Gr Postprints 2010, 23:77-87.

16. Briggs D, Seah MP (Eds): Practical Surface Analysis: Auger and X-Ray Photoelectron Spectroscopy. 2nd edition. New York: Wiley; 1997.

17. Stohr J. NEXAFS Spectroscopy New York: Springer; 1992

18. Cotte M, Susini J, Dik J, Janssens K: Synchrotron-based X-Ray absorption spectroscopy for art conservation: looking back and looking forward. Acc Chem Res 2010, 43:705-714.

19. Ade H, Urquhart SG: NEXAFS spectroscopy and microscopy of natural and synthetic polymers. In Chemical Applications of Synchrotron Radiation, Volume 12. Edited by Sham TK. Singapore: World Scientific Publishing; 2002:285-355.

20. Urquhart SG, Ade $\mathrm{H}$ : Trends in the Carbonyl Core (C 1S, O 1S) $\rightarrow \pi^{*} \mathrm{C}=0$ transition in the near-edge $\mathrm{X}$-ray absorption fine structure spectra of organic molecules. J Phys Chem B 2002, 106:8531-8538.

21. Stulik D, Miller D, Khanjian H, Khandekar N, Wolbers R, Carlson J, Petersen WC: Solvent Gels for the Cleaning of Works of Art: The Residue Question. Los Angeles: Getty Conservation Institute; 2004.

22. Wolbers RC, Norbutus A, Lagalante AF: Acrylic emulsion paints: preliminary extractive studies with two commercial paint systems. In New insights into the Cleaning of Paintings: Proc from Cleaning 2010 Int Conf Univ Politécnica Valencia and Museum Conserv Institute. Edited by Mecklenburg MF, Charola AE, Koestler RJ. Washington, DC: Smithsonian Institution Scholarly Press; 2013:147-157.

23. Dillon CE, Lagalante AF, Wolbers RC: Acrylic emulsion paint films: the effect of solution $\mathrm{pH}$, conductivity, and ionic strength on film swelling and surfactant removal. Stud Conserv 2014, 59:59-62. 
24. For detailed information about the NIST/Dow Soft XRay Materials Characterization Facility at the NSLS BNL [http://beamlines.ps.bnl.gov/ beamline.aspx?blid=U7A]

25. Ravel B, Newville M: ATHENA, ARTEMIS, HEPHAESTUS: data analysis for X-ray absorption spectroscopy using IFEFFIT. J Synchrotron Radiat 2005, 12(Pt 4):537-541.

doi:10.1186/s40494-014-0025-y

Cite this article as: Willneff et al.: Spectroscopic techniques and the conservation of artists' acrylic emulsion paints. Heritage Science 2014 2:25.

Submit your manuscript to a SpringerOpen ${ }^{\circ}$ journal and benefit from:

- Convenient online submission

- Rigorous peer review

- Immediate publication on acceptance

- Open access: articles freely available online

- High visibility within the field

- Retaining the copyright to your article

Submit your next manuscript at springeropen.com 